\title{
NASA Crew Launch Vehicle Approach Builds on Lessons from Past and Present Missions
}

\author{
Daniel L. Dumbacher \\ Deputy Manager, Exploration Launch Office \\ NASA Marshall Space Flight Center
}

The United States Vision for Space Exploration, announced in January 2004, outlines the National Aeronautics and Space Administration's (NASA) strategic goals and objectives, including retiring the Space Shuttle and replacing it with a new human-rated system suitable for missions to the Moon and Mars. The Crew Exploration Vehicle (CEV) that the new Crew Launch Vehicle (CLV) lofts into space early next decade will initially ferry astronauts to the International Space Station and be capable of carrying crews back to lunar orbit and of supporting missions to Mars orbit. NASA is using its extensive experience gained from past and ongoing launch vehicle programs to maximize the CLV system design approach, with the objective of reducing total lifecycle costs through operational efficiencies.

To provide in-depth data for selecting this follow-on launch vehicle, the Exploration Systems Architecture Study was conducted during the summer of 2005 , following the confirmation of the new NASA Administrator. A team of aerospace subject matter experts used technical, budget, and schedule objectives to analyze a number of potential launch systems, with a focus on human rating for exploration missions. The results showed that a variant of the Space Shuttle, utilizing the reusable Solid Rocket Booster as the first stage, along with a new upper stage that uses a derivative of the RS-25 Space Shuttle Main Engine to deliver 25 metric tons to low-Earth orbit, was the best choice to reduce the risks associated with fielding a new system in a timely manner.

The CLV Project, managed by the Exploration Launch Office located at NASA's Marshall Space Flight Center, is leading the design, development, testing, and operation of this new human-rated system. The CLV Project works closely with the Space Shuttle Program to transition hardware, infrastructure, and workforce assets to the new launch system, leveraging a wealth of lessons learned from Shuttle operations. 
The CLV is being designed to reduce costs through a number of methods, ranging from validating requirements to conducting trades studies against the concept design. Innovations such as automated processing will build on lessons learned from the Shuttle, other launch systems, Department of Defense operations experience, and subscale flight tests such as the Delta Clipper-Experimental Advanced (DC$X A)$ vehicle operations that utilized minimal touch labor, automated cryogenic propellant loading, and an 8-hour turnaround for a cryogenic propulsion system. For the CLV, the results of hazard analyses are contributing to an integrated vehicle health monitoring system that will troubleshoot anomalies and determine which ones can be solved without human intervention. Such advances will help streamline the mission operations process for pilots and ground controllers alike.

In fiscal year 2005, NASA invested approximately $\$ 4.5$ billion of its $\$ 16$ billion budget on the Space Shuttle. The ultimate goal of the CLV Project is to deliver a safe, reliable system designed to minimize lifecycle costs so that NASA's budget can be invested in missions of scientific discovery. Lessons learned from developing the CLV will be applied to the growth path for future systems, including a heavy lift launch vehicle. 